\title{
Investigation of Residual Stresses and Deformations of a Pultruded Thin Beam Profile
}

\author{
Endija Namsone \\ Institute of Materials and Structures \\ Riga Technical University \\ Riga, Latvia \\ endija.namsone@inbox.lv
}

\begin{abstract}
In the present study, a coupled 3D transient thermo-chemical analysis together with $2 \mathrm{D}$ plane strain mechanical analysis is carried out for the pultrusion process. For the mechanical analysis, a cure hardening instantaneous linear elastic (CHILE) approach is used of a thin beam profile made of glass fibre and epoxy resin. The applied approach is efficient and fast to investigate the residual stresses and deformations together with the distributions of temperature and degree of cure obtained from the thermochemical analysis.
\end{abstract}

Keywords - finite element method, pultrusion, residual stresses, thermo-mechanical.

\section{INTRODUCTION}

Characterization of mechanical behaviour is not only an important study for entire structures under loading [1]-[3], but also for the separate parts in time of their production [4] since stresses and deformations caused by the process may occur.

Pultrusion is a continuous and cost-effective process and is widely used for a production of high strength fibrereinforced polymer composite profiles with different crosssections [5], [6]. During pultrusion, the fibres are saturated with the resin in a tank and after that are continuously pulled through a heated die. In literature, many different numerical and experimental techniques are carried out to design pultrusion processes. Mostly, thermo-chemical modelling in transient and steady state analyses are developed for a better understanding of pultrusion processes to analyse the distributions of temperature and degree of cure inside the die, using the finite element methodology [7]-[9] finite difference methodology [10], [11], based on the nodal control volume method.

It is well known, that in time of manufacturing process of thermoset matrix composites, material characteristics of resin vary during the glass transitions from rubbery to solid state. It follows that, this change of resin material directly influences its mechanical properties, which are temperature- and degree of cure-dependent and can occur as unwanted residual deformations. Therefore, the investigation of process-induced variations like residual stresses and deformations should be performed for a better control of mechanical behaviour of pultrusion process.

In addition of thermo-chemical studies in literature, a thermo-chemical-mechanical analysis of pultrusion for glass-fibre reinforced profiles are developed in [12]-[14]. For this reason, in the present study a thermo-mechanical analysis is applied by coupling a 3D thermo-chemical model with a 2D plane strain mechanical model, like described in [15], [16]. The thermo-mechanical finite element model is created in the finite element code ANSYS Mechanical, based on the cure hardening instantaneously linear elastic method (CHILE) as in [17] to investigate the residual stresses and deformations of pultruded beam profile made of glass fibre and epoxy resin.

\section{MATERIALS AND METHODS}

\section{A. Formulation of multi-physical problem}

The simulation of 3D thermo-chemical pultrusion process can be solved by three governing energy equations:

$$
\begin{gathered}
\rho c_{p} \frac{\partial T}{\partial t}-\frac{\partial}{\partial x}\left(k_{x} \frac{\partial T}{\partial x}\right)-\frac{\partial}{\partial y}\left(k_{y} \frac{\partial T}{\partial y}\right)-\frac{\partial}{\partial z}\left(k_{z} \frac{\partial T}{\partial z}\right)=0 \\
\bar{\rho} \overline{c_{p}}\left(\frac{\partial T}{\partial t}+u \frac{\partial T}{\partial x}\right)-\frac{\partial}{\partial x}\left(\overline{k_{x}} \frac{\partial T}{\partial x}\right)-\frac{\partial}{\partial y}\left(\overline{k_{y}} \frac{\partial T}{\partial y}\right)-\frac{\partial}{\partial z}\left(\overline{k_{z}} \frac{\partial T}{\partial z}\right)- \\
q=0 \\
\left(\frac{\partial T}{\partial t}+u \frac{\partial T}{\partial x}\right)=R_{r}
\end{gathered}
$$


where $\mathrm{T}$ is the temperature, $u$ is the pull speed, $c_{p}$ is the specific heat, $\rho$ is the density, $k_{x}, k_{y}$ and $k_{z}$ are the thermal conductivities in $x, y$ and $z$ directions, $\mathrm{q}_{b}$ is the rate of energy, $\alpha$ is the degree of cure. Accordingly, $\bar{\rho}$ is the lumped density, $\overline{c_{p}}$ is the lumped specific heat, $\overline{k_{x}}, \overline{k_{y}}$ and $\overline{k_{z}}$ are the lumped thermal conductivities of the composite material in $x, y$ and $z$ directions. The generative term $q$ in a relation of internal heat generation and due to the exothermic reaction of resin can be expressed by the following equation:

$$
q=V_{r}+\rho_{r}+H_{t r}+R_{r}
$$

where $V_{r}$ is the resin volume fracture, $H_{t r}$ is the total heat of reaction, $\rho_{r}$ is the density of resin and $R_{r}$ is the resin reaction rate, which can be described as in [18]:

$$
R_{r}(\alpha, T)=\frac{\partial \alpha}{\partial t}=\frac{1}{H_{t r}} \frac{d H(T)}{d t}=K(T) \cdot f(\alpha)
$$

$f(\alpha)$ is the reaction function and $K(T)$ can be defined by the Arrhenius relationship:

$$
K(T)=K_{0} \exp \left(-\frac{E}{R T}\right)
$$

where $R$ is the universal gas constant and $E$ is the activation energy. $E$ and $K_{0}$ could be determined by a fitting procedure of the experimental heat flow curves obtained from differential scanning calorimetry tests.

For the thermo-chemical simulation of pultrusion process in this study, the equations above are solved using the finite element code ANSYS Mechanical and the nodal control volume method is applied to obtain the evolution of temperature and degree of cure.

Since the resin state changes during the process from rubbery to glassy state, the CHILE approach method is applied to capture the transition mechanically for the thermo-mechanical analysis. In this case, the resin modulus is described:

$$
\begin{aligned}
& E_{r}(\alpha, T)= \\
& \left\{\begin{array}{ccc}
E_{r}^{0} & T^{*}<T_{C 1} \\
E_{r}^{0}+\frac{T^{*}-T_{C 1}}{T_{C 2}-T_{C 1}}\left(E_{r}^{\infty}-E_{r}^{0}\right) & \text { for } & T_{C 1} \leq T^{*} \leq T_{C 2} \\
E_{r}^{\infty} & T^{*}>T_{C 2}
\end{array}\right.
\end{aligned}
$$

where $E_{r}^{0}$ and $E_{r}^{\infty}$ are the uncured and cured resin moduli, $T_{C 1}$ and $T_{C 2}$ are the critical temperatures at the begin and completion of the glass transition and $T^{*}$ is the difference between the instantaneous glass transition and resin temperature: $T^{*}=T_{g}-T$. The evolution of the glass transition is described as:

$$
T_{g}=T_{g}^{0}+\left(T_{g}^{\infty}-T_{g}^{0}\right) \frac{\lambda \alpha}{1-(1-\lambda) \alpha}
$$

$T_{g}^{0}$ and $T_{g}^{\infty}$ are the temperatures of glass transition of uncured and cured resin, $\lambda$ is a constant fitting parameter.
The chemical shrinkage of resin is calculated:

$$
\Delta \varepsilon_{r}=\sqrt[3]{1+\Delta V_{r}}-1
$$

where $\Delta V_{r}=\Delta \alpha \cdot V_{s h}$ - the incremental volume resin shrinkage as a function of change in the degree of cure and total volume shrinkage $V_{s h}=6.9 \%$.

The thermo-mechanical problem is solved by using the obtained distributions of temperature and degree of cure from the thermo-chemical analysis. For the finite element simulations in ANSYS, the incremental linear elastic approach is applied to calculate the residual stresses and deformations. The incremental thermal strains:

$$
\Delta \varepsilon_{i}^{t h}=\alpha_{i} \cdot \Delta T
$$

Mechanical properties of fibre and resin, fibre volume fracture and as well as the chemical resin shrinkage strains are affecting the incremental chemical shrinkage strains. Assuming the fibre phase mechanical properties are cure independent $\Delta \varepsilon_{1 f}=\Delta \varepsilon_{2 f}=\Delta \varepsilon_{3 f}=0$, then incremental chemical strain:

$$
\begin{aligned}
& \Delta \varepsilon_{1}^{c h}=\frac{\Delta \varepsilon_{r} E_{r}\left(1-V_{f}\right)}{E_{11 f} V_{f}+E_{r} \cdot\left(1-V_{f}\right)} \\
& \Delta \varepsilon_{2}^{c h}=\Delta \varepsilon_{3}^{c h}=\left(\Delta \varepsilon_{r}+v_{r} \Delta \varepsilon_{r}\right)\left(1-V_{f}\right)-\left(v_{12 f} V_{f}+\right. \\
& \left.v_{r}\left(1-V_{f}\right)\right) \Delta \varepsilon_{1}^{c h}
\end{aligned}
$$

where $E_{11 f}$ and $v_{12 f}$ is the longitudinal elastic modulus and Poisson's ratio of the fiber, $E_{r}$ and $v_{r}$ - of the resin, $V_{f}$ is the fibre volume ratio. $\Delta \varepsilon_{1}^{c h}$ - incremental chemical strain in the longitudinal direction, $\Delta \varepsilon_{2}^{c h}, \Delta \varepsilon_{3}^{c h}-$ in the transverse directions.

\section{B. Thermo-chemical model}

A 3D transient thermo-chemical analysis is carried out for a thin beam profile [12]. The pultrusion die for this profile is with following dimensions 915 x 38.1 x $38.1 \mathrm{~mm}$ and $1.59 \times 12.7 \mathrm{~mm}$ for the cross-section of it. The materials used for a production of beam are fiberglass and epoxy resin. The finite element model is created in ANSYS mechanical using 3D thermal solid finite elements Solid 70 and only a quarter is modelled due to the symmetry (see Fig.1). The total number of elements is 11102 and $3660 \mathrm{~mm}$ from the die exit of profile is continued to extend the thermo-chemical analysis. The initial conditions:

- at time $\mathrm{t}=0$ all nodal points have the room temperature and degree of cure is 0 ;

- $\quad$ pull speed $20 \mathrm{~cm} / \mathrm{min}$;

- $\quad$ solution time step is $4.5 \mathrm{~s}$. 


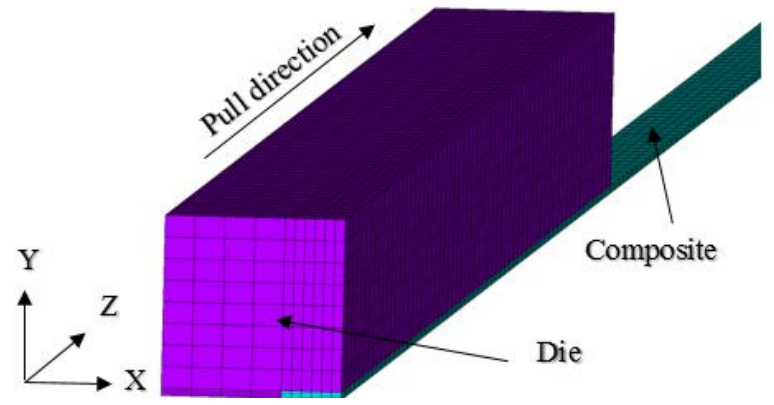

Fig. 1. Fragment of the finite element model for the thermo-chemical analysis.

\section{Thermo-mechanical model}

During the 2D thermo-mechanical analysis, the crosssection of beam profile is moved through the pull direction. The finite element model of profile cross section in ANSYS Mechanical is created by 2D plane strain solid finite elements Plane 182. The model has following boundary conditions - symmetry boundary conditions on the symmetry line and sliding conditions on the contact surfaces.

The mechanical properties of fibre and resin are given in Table 1. The value of CTE of resin in a glassy state is 2.5 times smaller than in a rubbery state. The critical temperature at the onset and competition of glass transitions is assumed $T_{C 1}=-45.7^{\circ} \mathrm{C}$ and $T_{C 2}=-12^{\circ} \mathrm{C}$. For the $T_{g}$ calculation in equation (8), $T_{g}^{0}$ is assumed $0{ }^{\circ} \mathrm{C}$ and $T_{g}^{\infty}=195^{\circ} \mathrm{C}$. The fitting parameter $\lambda=0.4$.

\section{RESULTS AND DISCUSSIONS}

It should be noted that all results for the thermomechanical analysis should be viewed together with the distributions of temperature and degree of cure obtained

TABLE 1 MECHANICAL PROPERTIES OF FIBRE AND RESIN

\begin{tabular}{|c|c|c|c|}
\hline \multirow{2}{*}{ Property } & \multicolumn{3}{|c|}{ Value } \\
\hline & $\begin{array}{c}\text { Symbol } \\
\text { (unit) }\end{array}$ & Fibre & Resin \\
\hline \multirow{4}{*}{ Young's modulus } & $E_{r}^{0}(\mathrm{MPa})$ & - & 3.447 \\
\hline & $E_{r}^{\infty}(\mathrm{MPa})$ & - & $3.447 \cdot 10^{3}$ \\
\hline & $E_{11}(\mathrm{MPa})$ & $7.308 \cdot 10^{4}$ & Eq. 11 [1] \\
\hline & $E_{22}(\mathrm{MPa})$ & $7.308 \cdot 10^{4}$ & Eq. 11 [1] \\
\hline \multirow{2}{*}{ Shear modulus } & $G_{12}(\mathrm{MPa})$ & $2.992 \cdot 10^{4}$ & Eq. 13 [1] \\
\hline & $G_{13}(\mathrm{MPa})$ & $2.992 \cdot 10^{4}$ & Eq. 13 [1] \\
\hline \multirow{2}{*}{ Poisson’s ratio } & $v_{12}$ & 0.22 & 0.35 \\
\hline & $v_{13}$ & 0.22 & 0.35 \\
\hline \multirow{2}{*}{$\begin{array}{l}\text { Coefficient of } \\
\text { thermal expansion } \\
\text { (CTE) }\end{array}$} & $\alpha_{1}\left(1 /{ }^{\circ} \mathrm{C}\right)$ & $5.04 \cdot 10^{-6}$ & $5.76 \cdot 10^{-5}$ \\
\hline & $\alpha_{2}\left(1 /{ }^{\circ} \mathrm{C}\right)$ & $5.04 \cdot 10^{-6}$ & $5.76 \cdot 10^{-5}$ \\
\hline
\end{tabular}

from the thermo-chemical analysis, which were measured in two different control points. As the temperature and degree of cure distributions are almost uniform all over the cross-section of profile, the results are practically the same for both control points. For this reason, the results of thermo-chemical analysis are presented only for one control point B (see Fig. 2).

The values of effective Young's moduli at the end of the pultrusion process are describing the final stiffness of beam profile. These values are found to be $48238.5 \mathrm{MPa}$ in the longitudinal direction and $12439.9 \mathrm{MPa}$ in the transverse direction. Comparing them with the recommended values found in literature [19], which is in the range of 35000 to $50000 \mathrm{MPa}$ for glass fibre reinforced composite, it can be concluded that the stiffness of this beam is adequate.

The evolution of corresponding strains are given in Fig.3. In this case, thermal strain is the incremental thermal strain and chemical strain is the linear chemical strain. The total strain is the process induced strain obtained by counting together thermal strain with chemical strain. The maximum value of thermal strain is $\varepsilon_{\max }^{\text {th }}=0.01116$.

\section{CONCLUSIONS}

In the present study, a thermo-chemical-mechanical analysis was performed with the aim to investigate the residual stresses and deformations for the pultrusion process of a rectangular thin beam profile. For this reason, a 3D thermo-chemical model was coupled with a 2D plane strain mechanical model performed in finite element code ANSYS Mechanical. In order to obtain the resin modulus, which is dependent of temperature and degree of cure, the CHILE based approach was utilized.

During the thermo-chemical analysis, uniform distributions of temperature and degree of cure were obtained all over the profile in both control points, where the process of curing were occurred very similarly at the same time.

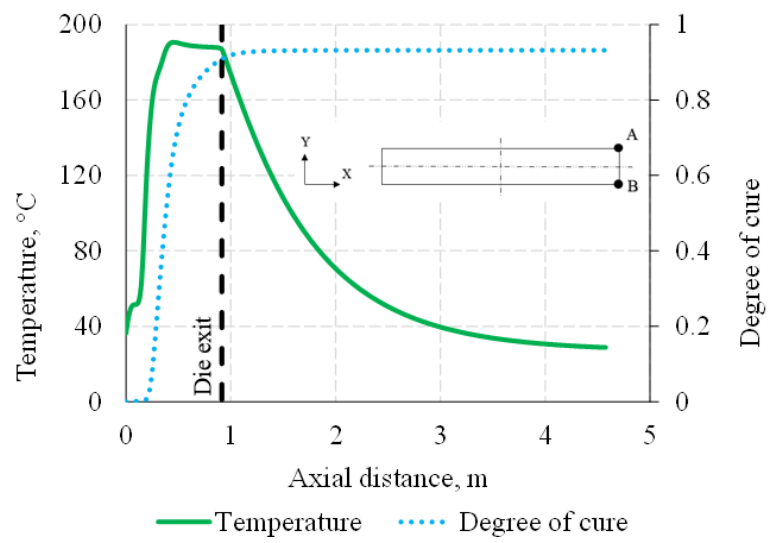

Fig. 2. The distribution of temperature and dregee of cure in the control point B. 


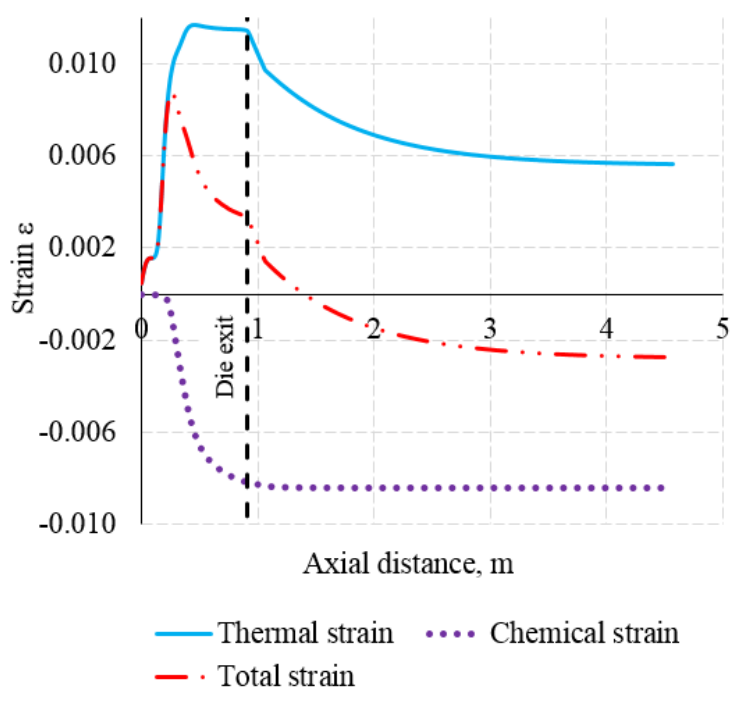

Fig. 3. The strain evolution in the control point B.

The obtained values of the effective elastic modulus of the composite material were analysed and compared with the recommendations in the literature, it can be concluded that the stiffness of beam profile is appropriate.

The applied method was found to be quite fast and efficient for the investigation of the residual stresses and deformations together with the distributions of temperature and degree of cure. It could be performed for further studies also for more complex pultruded profiles for different structures, where the geometrical precision is more important.

\section{ACKNOWLEDGEMENTS}

This work was supported by the European Regional Development Fund, project No. 1.1.1.1/18/A/053 “An effectiveness improvement of conventional pultrusion processes".

\section{REFERENCES}

[1] P. Masarati, M. Morandini, J. Riemenschneider, P. Wierach, S. Gluhih, E. Barkanov, "Optimal Design of an active twist 1:2.5 scale rotor blade,"in: Proceedings of the $31^{\text {st }}$ European Rotorcraft Forum, Firenze, Italy, pp. 37.1-37.14, 2005.

[2] E. Barkanov, E. Eglītis, F. Almeida, M. C. Bowering, G. Watson, "Optimal design of composite lateral wing upper covers. Part II: Nonlinear buckling analysis,” Aerosp. Sci. Technol. Vol. 51, pp. 87-95, 2016, https://doi./org/10.1016/j.ast.2016.01.020

[3] E. Barkanov, A. Kovalov, P. Wierach, J. Riemenschneider, "Optimised comparative analysis of an active twist for helicopter rotor blades with C and D-spar designs,” Mech. Compos. Mater. Vol. 5., pp. 553-566, 2018, https://doi.org/10.1007/s11029-0189764-2

[4] V. Antonucci, A. Cusano, M. Giordano, J. Nasser, L. Nicolais, "Cure-induced residual strain build-up in a thermoset resin," Composites: Part A, vol.37, pp. 592-601, 2006, https://doi.org/10.1016/j.compositesa.2005.05.016
[5] P. Akishin, E. Barkanov, A .Bondarchuk, "Finite element modelling and analysis of conventional pultrusion processes,” IOP Conf. Series: Materials Science and Engineering, vol. 96, p. 10, 2015, http://iopscience.iop.org/article/10.1088/1757899X/96/1/012012

[6] E. Barkanov, P. Akishin, R. Emmerich, M. Graf, "Numerical simulation of advanced pultrusion processes with microwave heating," in: Proceeding of the VII European Congress on Computational Methods in Applied Sciences and Engineering, 2016, pp. 7720-7738, https://doi.org/10.7712/100016.2368.5953

[7] E. Barkanov, P. Akishin, N.L. Miazza, S. Galvez, “ANSYS-based algorithms for a simulations of pultrusion processes,” Mech. Adv. Mater. Struc., vol. 5, pp. 377-384, 2017, https://doi.org./10.1080/15376494.2016.1191096

[8] E. Barkanov, P. Akishin, N.L. Miazza, S. Galvez, N. Pantelelis, "Experimental validation of thermo-chemical algorithm for a simulation of pultrusion processes," IOP Conf. series: Journal of Physics:Conf. series, vol. 991, 2018, 0.1088/1742$\underline{6596 / 991 / 1 / 012009}$

[9] E. Barkanov, P. Akishin, E. Namsone, A. Bondarchuk, N. Pantelelis, "Real time characterization of pultrusion processes with a temperature control,” Mech. Compos. Mater., vol. 56, pp. 135148, 2020, https://doi.org/10.1007/s11029-020-09868-4

[10] Y. R. Chachad, J, A, Roux, J. G. Vaughan, E. S. Arafat, “Thermal model for three-dimensional irregular shaped pultruded fiberglass composites,” J. Compos. Mater, vol. 6, pp. 692-721, 1996, https://doi.org/10.1177/002199839603000604

[11] I. Baran, C.C. Tutum, J. H. Hattel, "The effect of thermal contact resistance on the thermosetting pultrusion processes," Composites: Part B, vol. 45, pp. 995-1000, 2013, https://doi.org/10.1016/j.compositesb.2012.09.049

[12] I. Baran, C. C. Tutum, M. W. Nielsen, J. H. Hattel, "Process induced residual stresses and distortions in pultrusion," Composites:Part B, vol. 51, pp. 148-161, 2013, http://dx.doi.org/10.1016/j.compositesb.2013.03.031

[13] I. Baran, J. H. Hattel, R. Akkerman, "Investigation of process induced warpage for pultrusion of rectangular hollow profile," Composites:Part B, vol. 68, pp. 365-374, 2015, http://dx.doi.org/10.1016/j.compositesb.2014.07.032

[14] T. A. Bogetti and J. W. Gillesprie, "Process-induced stress and deformation in thick-section thermoset composite laminates," J. Compos. Mater., vol. 26, pp. 626-660, 1992, https://doi.org/10.1177/002199839202600502

[15] A. Johnston, R. Vaziri, A. Poursartip, "A plane straine model for process-induced deformation of laminated composite structures,” J. Compos. Mater., vol. 35, pp. 1435-1469, 2001, https://www.researchgate.net/publication/254112346

[16] I. Baran, J. H. Hattel, R. Akkerman, C. C. Tutum, "Mechanical modelling of pultrusion process: $2 \mathrm{D}$ and $3 \mathrm{D}$ numerical approaches,” Appl. Compos. Mater., vol. 22, pp. 99-118, 2015, https://doi.org/10.1007/s10443-014-9394-3

[17] I. Baran, J.H. Hattel and C. C. Tutum, "The impact of process parameters on the residual stresses and distortions in pultrusion ,“ in $19^{\text {th }}$ International Conference on Composite Materials, 2013, pp. 6328-6337.

[18] P. Akishin, E. Barkanov, N. Miazza, S. Galvez, "Curing kinetic models of resins for microwave assisted pultrusion,” Key Eng. $\begin{array}{llll}\text { Mater., } & \text { vol. } & \text { 721, } & \text { pp. }\end{array}$ https://doi.org/10.4028/www.scientific.net/KEM.721.92

[19] D. Zenkert and M. Battley, Laminate and Sandwich Structures: Foundations of fibre composites. $2^{\text {nd }}$ edition. Denmark: Polyteknisk Forlarg, 2009. 